\title{
Bismuth/hydroxyapatite-modified carbon screen-printed electrode for heavy-metal ion detection in aqueous media
}

\author{
Aamir Amanat Ali Khan ${ }^{1}$, Huma Ajab ${ }^{2}$, Asim $\mathrm{Yaqub}^{3}$, and Mohd Azmuddin Abdullah, ${ }^{4}$ \\ ${ }^{1}$ Department of Chemical Engineering, Universiti Teknologi PETRONAS, Seri Iskandar, Perak, 32610, Malaysia \\ ${ }^{2}$ Department of Chemistry, COMSATS Institute of Information Technology, Abbottabad, 22060, Pakistan \\ ${ }^{3}$ Department of Environmental Sciences, COMSATS Institute of Information Technology, Abbottabad, 22060, Pakistan \\ ${ }^{4}$ Institute of Marine Biotechnology, Universiti Malaysia Terengganu, Kuala Nerus, Terengganu, 21030, Malaysia
}

\begin{abstract}
Square-wave voltammetric stripping analysis is attractive for environmental monitoring and trace metal ion determination. The sensitivity is a result of analytes preconcentration steps on the electrode and advanced measurement procedures, where metal analytes are stripped away from the electrode at appropriate potential scan. Screen-printed electrode (SPE) has great advantages for in situ assays of heavy metal ions. Modification of SPE with bismuth (Bi) film improves the amalgamation of metal ions and the addition of hydroxyapatite (HA) increases the ion sorption, and enhances the current response due to the large porous structure and surface active sites for the metal ion binding. The ionization of the functional groups on the electrode surface upon contact with the aqueous system further assists the cation binding. The analytical performance of $\mathrm{Bi}$ and HA-modified SPE for simultaneous detection of $\mathrm{Cd}(\mathrm{II})$ and $\mathrm{Pb}$ (II) ions by square wave anodic stripping voltammetry (SWASV) was evaluated. Under the optimized electrochemical working conditions, calibration graph is linear for $240 \mathrm{~s}$ deposition time, in $0.1 \mathrm{M}$ acetate buffer at $\mathrm{pH} 7.6$ with the detection limit of $16.8 \mathrm{ppb}$ for $\mathrm{Pb}$ (II). Two peaks corresponding to $\mathrm{Cd}(\mathrm{II})$ at $-0.8 \mathrm{~V}$ and $\mathrm{Pb}$ (II) at $-0.6 \mathrm{~V}$ can be discerned suggesting that Bi-HA modification had increased the current responses.
\end{abstract}

\section{Introduction}

Heavy metals are non-biodegradable and follow a cycle in the environment which include water (surface, ground, precipitation), air (particulate matter), soil (bottom sediment) and biosphere (plants, animals, fish, human). Among the priority heavy metal pollutants are lead, cadmium, and mercury [1]. These may be retained indefinitely in the eco-systems and food chain. Lead accumulation has harmful effects on soil microflora and crop growth which will eventually affect the food safety [2]. Lead exposure has caused numerous health effects such as lifelessness, tetchiness, reduced attention span and memory loss, and decreased glutathione in red blood cells which may lead to hallucination, convulsions, paralysis, coma and death $[3,4]$. Excessive cadmium can lead to hypertension, immuno-suppression, emphysema, kidney failure, bone demineralization, neurotoxicity and induce cancer $[5,6]$.
The maximum allowable limit for heavy metals in water set by the US Environmental Protection Agency is (ppm) 0.002 (mercury), 0.005 (cadmium) and 0.015 (lead) [7]. Environmental monitoring is therefore crucial to evaluate the disturbances to environmental cycles so that strategies can be devised to allow control and mitigation of any potential disaster. One of the Principal of Green Chemistry is to promote analytical methodology development for real-time analysis, in-situ monitoring and management before hazardous substances formation [8,9]. Screen-printed electrode (SPE) is promising for this in situ assay due to its versatility, disposability, ease of preparation, tailored capability and affordability through electronic, optical, or micro-gravimetric signal transduction. Screen-printing technology enables mass production of portable systems in the market with the development of disposable SPE as a new dimension in electrochemical-analysis for realtime, non-invasive analysis of a sample [10-14]. The attractiveness is boosted by the possibility of fabricating SPE into the microelectrodes and incorporation into highly sensitive biosensors [15-18]. SPEs are versatile through preparation in machine-controlled manufacturing, for low cost production of carbon inkbased electrodes of small dimensions, and planar configuration [15] and suitable as single-use sensors.

\footnotetext{
* Corresponding author: azmuddin@umt.edu.my
} 
Modification of sensor surface is one of the methods to enhance the sensitivity and selectivity of detection. Bismuth (Bi) has low toxicity with widespread pharmaceutical use [19]. Different types of Bi electrodes have been developed for analysis of inorganic ions and organic compounds [20] such as Bi-film and Bi-bulk film electrodes [2121,22], Bi-microelectrode and microelectrode arrays [2323,24], Bi-nanoparticle modified electrodes [25], graphene/ $\mathrm{Bi}$ nanocomposite film-modified glassy carbon electrode [2626], $\mathrm{Bi} /$ electrochemically reduced graphene/ionic liquid composite modified SPE [2727], Bi-film/crown ether/Nafion modified SPE [28], Bi-film SPE [29] and micro-patterned reduced graphene oxide/carbon nanotube/Bi composite electrodes [30]. The analytical properties are attributed to the property of $\mathrm{Bi}$ to form "fused alloys" with heavy metals, analogous to the amalgams that mercury forms [19].

Hydroxyapatite (HA), the main constituent of bones and teeth, is a bioactive ceramic material with high bioaffinity and biocompatibility. HA consists mainly of calcium phosphate, with sorption capacity for divalent heavy metal ions. The metal ions interact with HA modified electrode by pre-concentration with surface complexation, followed by simultaneous adsorption on HA, and calcium ion substitution coupled with diffusion on the electrode surface. Bi nanoparticles [31], HA [32] and Bi-HA [33] have been used as modifiers, with resulting higher sensitivity. We have recently reported the Limit of Detection (LOD) and Limit of Quantification (LOQ) of the carbon-modified electrode based on cellulose-HA composite which achieves 0.11 ppb LOD and 0.36 LOQ for trace $\mathrm{Pb}$ (II) ion detection in blood serum [3434]. To the best of our knowledge, the $\mathrm{Bi}-\mathrm{HA}$ SPE has not yet been reported for simultaneous detection of $\mathrm{Pb}$ (II) and $\mathrm{Cd}(\mathrm{II})$ ions.

In this study, Bi film and HA was applied on the SPE and the effects were compared with the carbon paste electrodes (CPE) for the detection of $\mathrm{Pb}^{2+}$ and $\mathrm{Cd}^{2+}$ ions in aqueous media. The main objectives were to develop robust, portable and user-friendly detection methods based on BiHA-modified SPE.

\section{Materials and methods}

\subsection{Chemicals and SPE}

HA (Sigma-Aldrich), $\mathrm{Bi}\left(\mathrm{NO}_{3}\right)_{2}$ (Merck) and all the chemicals used were of analytical grade.

The commercial SPE (Figure 1) was a $4 \mathrm{~mm}$ diameter probe from DropSens (Asturias, Spain), connected to the DropSens potentiostat ( $\mu$ Stat400) by a flexible cable (Connector, DropSens). A complete electrochemical cell with three electrodes was in one single strip consisting of graphite working electrode (WE) for modifier application, a graphite counter electrode (CE) and a silver pseudo-reference electrode (RE).

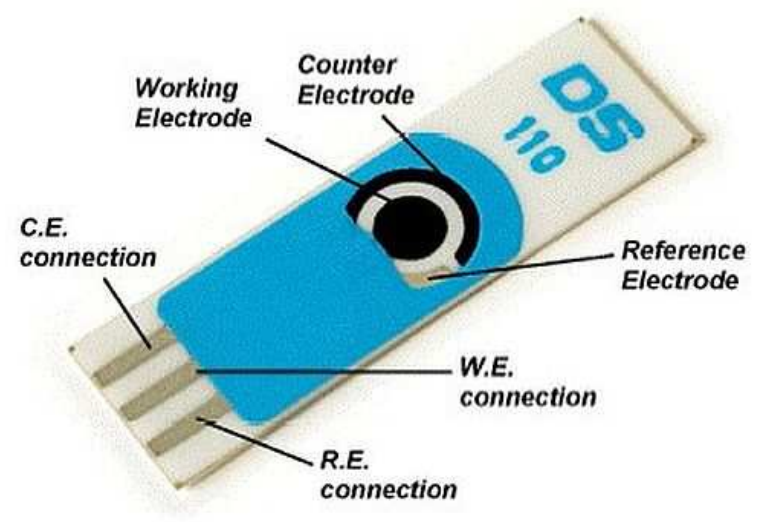

Fig. 1. Dropsens carbon SPE [35].

\subsection{Ex situ modification}

The SPE was immersed in $20 \mathrm{~mL}$ of $0.2 \mathrm{M}$ acetate buffer solution ( $\mathrm{pH} 4.5$ ) containing $500 \mathrm{ppb} \mathrm{Bi}(\mathrm{II})$ for modification of WE. The solution was degassed under vacuum for $10 \mathrm{~min}$, and the deposition potential of -1.0 $\mathrm{V}$ was applied for $240 \mathrm{~s}$ with solution stirred, followed by a rest period (without stirring) of $20 \mathrm{~s}$. This allowed Bi(II) film to be deposited and the modified SPE was rinsed carefully with deionized water. The $\mathrm{Bi}$ solution was then replaced in the cell by analyte solution. For comparison, an $\mathrm{Hg}$ film deposition was also carried out, only that the SPE was immersed in $20 \mathrm{~mL}$ of $0.2 \mathrm{M}$ acetate buffer solution ( $\mathrm{pH} 4.5$ ) containing $500 \mathrm{ppb}$ $\mathrm{Hg}^{2+}$. Once the $\mathrm{Hg}$ film was deposited, SPE was rinsed carefully with deionized water and the $\mathrm{Hg}^{2+}$ solution replaced.

\subsection{In situ modification}

One common technique of applying HA modification is a simple layer application by mixing HA with graphite in the form of paste, before applying on the SPE surface. HA-graphite was applied to the $4 \mathrm{~mm}$ diameter working area surface and left to dry at room temperature. In another technique, $10 \mathrm{mg} \mathrm{HA}$ was dissolved in $10 \mathrm{~mL}$ deionized water, followed by ultrasonication for $20 \mathrm{~min}$. Subsequently, $5 \mu \mathrm{L}$ of HA was dropped on the electrode surface and left to dry for $1 \mathrm{hr}$.

\subsection{SPE analysis}

Electrochemical measurements (cyclic voltammetry (CV) and square-wave voltammetry (SWV)) were performed using a portable, handheld, $\mu$ Stat400 batteryoperated bipotentiostat/galvanostat (DropSens, Spain). It was connected to a computer via USB and Bluetooth and controlled by Dropview software version 2.9 for Windows Vista and Windows 7 (DropSens, Spain). 
For analyte measurement, $100 \mu \mathrm{L}$ of test solution was placed on the WE area (4 $\mathrm{mm}$ diameter) of a modified SPE, ensuring that the area was completely covered by the drop. This was followed by the application of SWV using a square-wave potential ramp with a frequency of $25 \mathrm{~Hz}$, a potential step of $4 \mathrm{mV}$, and amplitude of $25 \mathrm{mV}$. The electrochemical accumulation step was at $-1.0 \mathrm{~V}$ for $120 \mathrm{~s}$, an equilibration period was $15 \mathrm{sec}$, and the SWV stripping scan was from -1.0 to $-0.2 \mathrm{~V}$

\subsection{Process parameters}

Heavy metal analyses of modified electrodes depend mainly on the process conditions. SWV was applied to modified electrodes under different electrolytes $(\mathrm{HCl}$, $\mathrm{KCl}, \mathrm{NaCl}, \mathrm{NaH}_{2} \mathrm{PO}_{4}$ and acetate buffer), $\mathrm{pH}$, deposition potential and deposition time to investigate enhanced conditions for voltammetric analysis.

\subsection{Calibration, validation and data analyses}

Calibration was obtained by a standard addition method by first measuring the peak area/peak height of current response curve of the sample with an unknown concentration. The $1000 \mathrm{mg} / \mathrm{L}$ calibration standard solutions of $\mathrm{Cd}$ and $\mathrm{Pb}$ in $0.05 \mathrm{M} \mathrm{HNO}_{3}$ were used as standards. Standard solutions for calibration were prepared by diluting appropriate volume of $1000 \mathrm{mg} / \mathrm{L}$ calibration standard solutions with $1 \% \mathrm{KNO}_{3}$.

To calibrate heavy metal analysis in environmental water sample, results obtained with modified electrodes were compared with the atomic absorption spectrometer (AAS) (Hitachi Z-5000, Japan) with a graphite lamp. The AAS was calibrated with standard solutions prior to the determination of the detection and quantification limits. Standard method for analyzing heavy metal ions in trace quantities was employed using an AAS. Five standard solutions were prepared ranging from $4 \mathrm{ppb}$ to $50 \mathrm{ppb}$ in $10 \mathrm{~mL}$ volumetric flasks.

The calibration curve was established as follows:

$$
\Delta \mu \mathrm{A}=b(\mathrm{~Pb} \text { conc. })+a
$$

where $\Delta \mu \mathrm{A}=I_{p}-I_{b}, I_{p}$ is the peak current $(\mu \mathrm{A}), I_{b}$ is the base-line current $(\mu \mathrm{A}), a$ is the intercept, and $b$ is the slope.

The LOD and LOQ were calculated as follows $[36,37]$ :

$$
\mathrm{LOD} \text { or } \mathrm{LOQ}=k(\text { S.D. } a) / b
$$

where $k=3$ (for LOD) ; and $k=10$ (for LOQ); S.D. $a$ is the standard deviation of the intercept; and $b$ is the slope.

\section{Results and discussions}

\subsection{Electrode synthesis}

The SEM, FESEM, FTIR and the XRD analyses have been reported before to elucidate the interaction of the material with the substrate [33]. The SEM and FESEM micrographs suggest that the powdered layer of the HA exhibits meso-porous particles of $150 \pm 50 \mathrm{~nm}$ in length, and the EDX spectra of HA demonstrates the presence of $\mathrm{P}$ and $\mathrm{Ca}$ peaks. The HA distribution in between the graphite flakes of the HA-modified carbon electrode (HA-CME) surface was disorderly, suggesting higher surface area for metal ions sorption. The IR spectra of the HA powder demonstrates the typical absorption bands related to the bands of phosphate, hydroxyl, water, and hydrogen phosphate. It is possible that the heavy metal ion sorption in HA may take place at the hydroxide and carbonate groups [3333]. The XRD pattern show the broad diffraction peaks corresponding to the Ca-HA [3838], which indicate the low crystallinity of HA with mesoporous structure and the $d$-spacing of $1.227 \AA$. The small $d$-spacing may actually highlight the potential of the metal ions being sorbed and held within the sorption sites, and not easily leaked out [33].

\subsection{Voltammetric characteristics}

Electrochemical interactions at the SPE surface were examined with $\mathrm{CV}$ to evaluate the changes in electron transfer at the surface of the modified electrode. Figure 2 shows the voltammograms for HA-modified SPE from $\mathrm{CV}$ at the scan rate of $25 \mathrm{mV} / \mathrm{s}-1.0 \mathrm{~V} / \mathrm{s}$ using $5.0 \mathrm{mM}$ $\mathrm{K}_{3} \mathrm{Fe}(\mathrm{CN})_{6}$ as the test probe in $0.1 \mathrm{M} \mathrm{KCl}$. Increase in scan rate had resulted in an increase in the electron transfer as evident in the increased peak potential difference $\left(\Delta E_{p}\right)$ between anodic and cathodic potential.

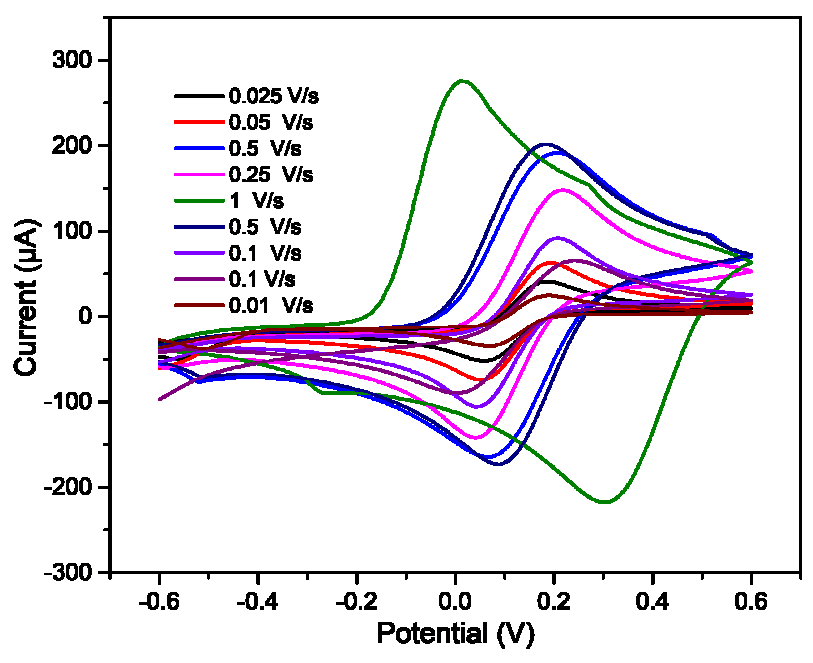

Fig. 2. Cyclic voltammogram of BiHA-SPE in supporting electrolyte $0.1 \mathrm{M} \mathrm{KCl}$ with $\mathrm{pH} 5.6$ at the scan rate of $25 \mathrm{mV} / \mathrm{s}$ to $1.0 \mathrm{~V} / \mathrm{s}$. 


\subsection{Improvement of the BiHA-SPE conditions}

Improvement studies were carried out using square-wave anodic stripping voltammetry (SWASV) measurements. In theory, when the potential reaches its characteristic oxidation potential, unique for each metal [3939], the metal gets stripped out from the electrode surface with the generation of oxidation signal. The $I_{p}$ is the measuring signal that transforms into the anodic current at these potentials which is proportional to the analyte concentration in the sample [4040,41]. The reaction of interest occurs at the WE which behaves as a cathode, where metal ions such as $\mathrm{Pb}^{2+}$ are reduced into metals in their metallic forms, $\mathrm{Pb}$, as shown in the following mechanism:

$$
\begin{aligned}
& \mathrm{Pb}^{2+}+2 \mathrm{e}^{-} \rightarrow \mathrm{Pb} \text { (Reduction) } \\
& \mathrm{Pb} \rightarrow \mathrm{Pb}^{2+}+2 \mathrm{e}^{-} \text {(Oxidation) }
\end{aligned}
$$

For $\mathrm{Pb}^{2+}$ to be reduced, the potential should be low enough, called the deposition potential. After the period of deposition, the potential is increased linearly (linear potential scan) and $\mathrm{Pb}$ starts to be oxidized at the same WE (serves as an anode) causing a sharp increase in current. As the deposited $\mathrm{Pb}$ is consumed, the current drops at low level (to give the first peak of $\mathrm{Pb}$ ).

The supporting electrolyte and the $\mathrm{pH}$ effects on the Bi-HA SPE were investigated by adding $0.1 \mathrm{M} \mathrm{HNO}_{3}$, $0.1 \mathrm{M} \mathrm{HClO}_{4}, 0.1 \mathrm{M} \mathrm{HCl}$ and $0.1 \mathrm{M}$ acetate buffer at various pHs. Higher $I_{p}$ of $\mathrm{Pb}^{2+}$ and $\mathrm{Cd}^{2+}$ were achieved in $0.1 \mathrm{M}$ acetate buffer at $\mathrm{pH}$ 7.6. Acidic medium is suitable for relegation of $\mathrm{Pb}$ as shown in Equation 5 and 6 where $\mathrm{Pb}(\mathrm{II})$ species leach out from the $\mathrm{HA}$ at the electrode/solution interface and can be detected directly by reduction [42].

$$
\begin{gathered}
\mathrm{HA}-\mathrm{Pb}(\mathrm{II}) \rightarrow \mathrm{HA}+\mathrm{Pb}(\mathrm{II}) \\
\mathrm{Pb}(\mathrm{II})+2 \mathrm{e}^{-} \rightarrow \mathrm{Pb}(0)
\end{gathered}
$$

The decreased $I_{p}$ of $\mathrm{Pb}^{2+}$ and $\mathrm{Cd}^{2+}$ in nitric acid and perchloric acid may probably be due to their oxidizing properties, resulting in the reduction of gaseous electroinactive products, $\mathrm{NO}_{2}$ and $\mathrm{ClO}_{2}$, during deposition step. This is attributed to the kinetic polarization, thus shifting the reduction potentials of ions to the more negative potentials [43]. It is important to fix the accumulation potential $\left(E_{a c c}\right)$ and the time $\left(t_{a c c}\right)$ during the SWV studies. The influences of the $E_{a c c}$ on the reduction peaks of $\mathrm{Pb}^{2+}$ and $\mathrm{Cd}^{2+}$ were studied over the range of -1.4 to $-0.6 \mathrm{~V}$. The plot of stripping $I_{p}$ as a function of $E_{a c c}$ suggested the maximum $I_{p}$ at $-1 \mathrm{~V}$ (data not shown). Thus, the accumulation potential of $-1 \mathrm{~V}$ was chosen for subsequent experiments. Variation of the $t_{a c c}$ from 1-3 min showed that the $I_{p}$ increased with the increasing $t_{a c c}$. The peak height reached plateau after $240 \mathrm{~s}$, and the higher current response was obtained at the potential lower than $-0.8 \mathrm{~V}$ (data not shown). This was however achieved with high background current, presumably due to the saturation of the electrode surface with the adsorbed layer of metals. Thus, deposition time of $240 \mathrm{~s}$ was used throughout, as it combined good sensitivity and relatively short analysis time.

\subsection{Performance enhancement of the BiHA-SPE}

HA-added SPE was modified by Bi film through in situ deposition with $\mathrm{Pb}^{2+}$ and $\mathrm{Cd}^{2+}$ ions. The stripping peak current was affected by the thickness of the Bi film, and this was controlled by the concentration of the Bi film. The effect of the concentration of the Bi film on the peak currents of $\mathrm{Cd}^{2+}$ was investigated at the concentration range of 100 to $1000 \mathrm{ppb}$ (Figure 3). As the $\mathrm{Bi}$ concentration was increased, the stripping peak current of $\mathrm{Cd}^{2+}$ was increased up to $500 \mathrm{ppb}$ and then remaining constant with small increment at $1000 \mathrm{ppb}$. Therefore, the $\mathrm{Bi}$ concentration of $500 \mathrm{ppb}$ was chosen for the determinations of $\mathrm{Pb}^{2+}$ and $\mathrm{Cd}^{2+}$ using BiHA-SPE.

Further enhancement of the BiHA-SPE performance involved varying the square-wave parameters such as the frequency, pulse amplitude and step potential. The frequency of $150 \mathrm{~Hz}$, pulse amplitude of $25 \mathrm{mV}$, and the step potential of $4 \mathrm{mV}$ were chosen as the step potential in the analysis for enhanced performance. In SWV, interferences may be attributed to competitive ions and complexes on the electrode surface. The effects of these ions were analyzed using a fixed amount of $\mathrm{Pb}^{2+}$ and $\mathrm{Cd}^{2+}$ and different concentrations of other ions/complexes. Interfering ions $\left(\mathrm{Cu}^{2+}\right.$ and $\left.\mathrm{Zn}^{2+}\right)$ at 100 $\mathrm{ppb}$ produced analyte error less than $5 \%$ for $20 \mathrm{ppb}$ of $\mathrm{Pb}^{2+}$ and $\mathrm{Cd}^{2+}$, are deemed acceptable. However, the presence of $\mathrm{Fe}^{2+}$ at $100 \mathrm{ppb}$ affected the $\mathrm{Cd}^{2+}$ determination but was tolerable for $\mathrm{Pb}^{2+}$.

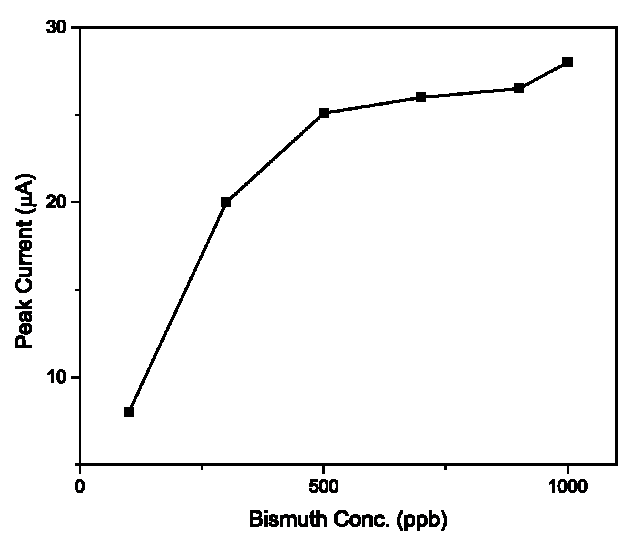

Fig. 3. Stripping voltammogram for $\mathrm{Cd}^{2+}$ with $\mathrm{Bi}-\mathrm{HA} \mathrm{SPE}$ in acetate buffer at $\mathrm{pH} 7.6,240 \mathrm{~s}$ deposition time.

\subsection{Calibration and validation}

BiHA-SPE was utilized to evaluate different concentrations of $\mathrm{Pb}^{2+}$ in the presence of $\mathrm{Cd}^{2+}$ under enhanced conditions (Figure 4). Two peaks corresponding to $\mathrm{Cd}^{2+}$ at $-0.8 \mathrm{~V}$ and $\mathrm{Pb}^{2+}$ at $-0.6 \mathrm{~V}$ can be discerned suggesting that the application of $\mathrm{BiHA}$ modifier had increased the current response for BiHA$\mathrm{SPE}$ for $\mathrm{Pb}^{2+}$ detection. The response of the proposed electrode was linear for $\mathrm{Pb}^{2+}\left(R^{2}=0.9777\right)$. The $R^{2}$ of 
0.9959 was obtained for $\mathrm{Cd}^{2+}$ but only based on 3 points and therefore the calibration curve is not shown.

The LOD of $\mathrm{Pb}^{2+}$ was $16.8 \mu \mathrm{g} / \mathrm{L}$, and the LOQ was $56.2 \mu \mathrm{g} / \mathrm{L}$. The LOD and LOQ for $\mathrm{Cd}^{2+}$ was not considered due to the lack of valid points on the standard curve. The values were within suitable range for the detection of ultratraces of $\mathrm{Pb}^{2+}$ in water samples. The LOD and LOQ of BiHA SPE can be further optimized with better composite material such as that based on cellulose-HA composite [34]. This signifies the importance of high sensitivity and selectivity of the method that will be employed for analyses of water samples.

Both the interaction of $\mathrm{HA}$ and alloy formation of $\mathrm{Bi}$ at the SPE surface with metal ions resulted in good reproducibility and selectivity. $\mathrm{HA}$ interacts with $\mathrm{Pb}^{2+}$ and $\mathrm{Cd}^{2+}$ at the electrode surface and the addition of $\mathrm{Bi}$ film along with HA film at the SPE surface enhanced the peak current response and can be explored further within the mechanical manufacturing set-up for sensor fabrication. SPE has the advantages of compact size, in situ modification and simplicity. The performance of BiHA SPE can be expected to improve with further optimization on electrode modification preparation. Electrochemical characterization and good response for heavy metal ions detection proved the feasibility of BiHA-SPE as a potential low cost, disposable electrodes for robust and on-site environmental monitoring.

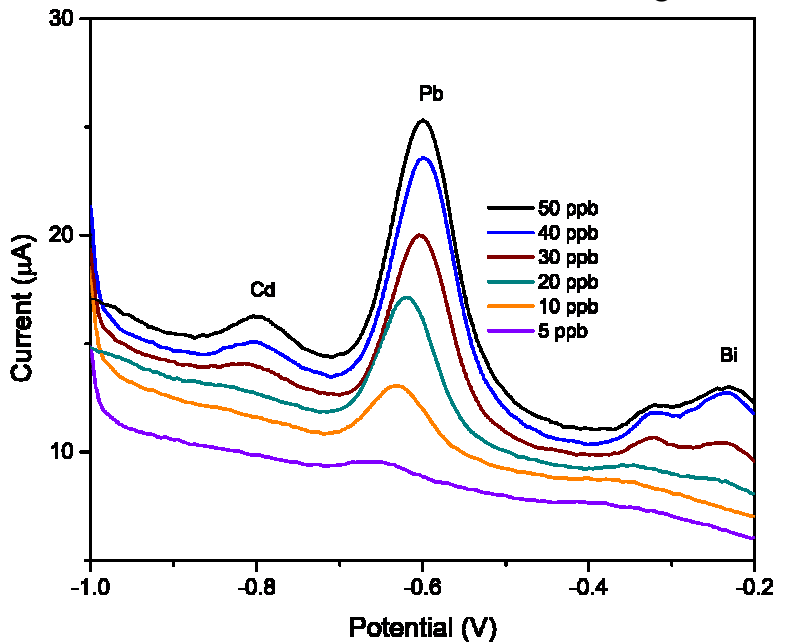

(a)

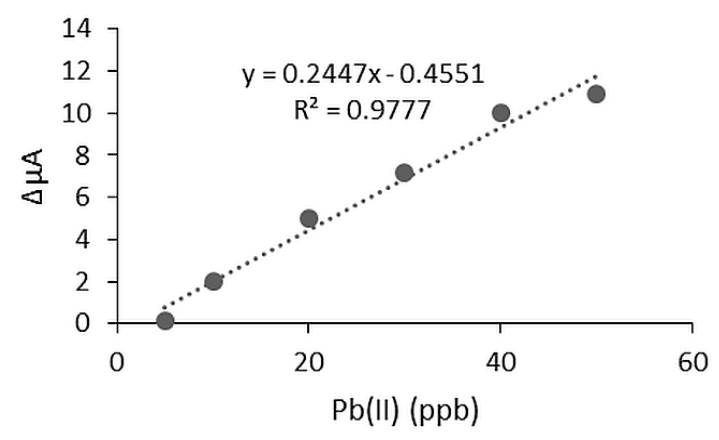

(b)

Fig. 4. a) Stripping voltammogram for different $\mathrm{Pb}^{2+}$ and $\mathrm{Cd}^{2+}$ concentrations, b) calibration plot for $\mathrm{Pb}^{2+}$ concentration, with Bi-HA SPE in acetate buffer at $\mathrm{pH} 7.6,240 \mathrm{~s}$ deposition time, and $\mathrm{Bi}$ at $500 \mathrm{ppb}$.
In order to test the validity of the developed BiHA$\mathrm{SPE}$, the electrochemical determination of $\mathrm{Pb}^{2+}$ ions in different lake water samples was carried out at enhanced conditions. The results were compared with the analyses from the AAS (Table 1). It was clear that the $\mathrm{Pb}^{2+}$ ions detection by the BiHA-SPE was comparable to AAS. Bi solid particles have been the main component of the modified SPE surface [20,44]. The particles incorporate and form deposits of metallic bismuth at the SPE surface, followed by the reduction at the oxidation/deposition potential. Comparison of BiHAmodified Carbon Electrode (BiHA-CME) and BiHASPE however suggested that the BiHA-CME demonstrated better recovery for $\mathrm{Pb}^{2+}$ and $\mathrm{Cd}^{2+}$ [33] as compared to the Bi-HA SPE. Further optimization is required with regards to $\mathrm{BiHA} \mathrm{SPE}$ fabrication to improve sensitivity and selectivity. However, Bi film with HA deposition in the carbon matrix offers a good stripping peak having favorable signal-to-background ratio, and relatively free from oxygen interferences during SWV measurements. Well-defined peaks corresponding to $\mathrm{Pb}^{2+}$ and $\mathrm{Cd}^{2+}$ can be discerned for the developed BiHA-SPE.

Table 1. Determination of $\mathrm{Pb}(\mathrm{II})$ ions from the spiked lake water sample.

\begin{tabular}{|c|c|c|c|}
\hline Sample & $\begin{array}{c}\text { Spiked } \\
\text { sample } \\
(\mu \mathrm{g} / \mathrm{L})\end{array}$ & $\begin{array}{c}\text { Bi-HA } \\
\text { SPE* } \\
(\boldsymbol{\mu g} / \mathbf{L})\end{array}$ & $\begin{array}{c}\mathbf{A A S} * \\
(\boldsymbol{\mu g} / \mathbf{L})\end{array}$ \\
\hline $\mathrm{A}$ & 80 & $71 \pm 4$ & $79 \pm 1$ \\
\hline $\mathrm{B}$ & 50 & $45 \pm 2$ & $48 \pm 1$ \\
\hline
\end{tabular}

* Electrode analysis consists of mean for 3 replicates with standard errors

\section{Conclusion}

The application of BiHA modifier had increased the current response for $\mathrm{Pb}^{2+}$ as low as $16.8 \mu \mathrm{g} / \mathrm{L}$. SPE had the advantages for on site application due to its compact, small size, in situ modification, without complicated precleaning. Electrochemical characterization and good response for heavy metal ion detection confers BiHASPE as a superior alternative to mercury based electrodes as economical, disposable electrodes for environmental monitoring.

The authors acknowledge the scholarship to Aamir Amanat Ali Khan by Universiti Teknologi PETRONAS (UTP) and the research facilities. This research was partly funded by Biomedical Technology Mission-Oriented Research (MOR). 


\section{References}

1. UNEP, Meeting on the Implementation of NAPs and the Preparation of Legally Binding Measures and Timetables required by Art. 15 of the LBS Protocol (Aix-en-Provence, France, 2008)

2. A. Kushwaha, N. Hans, S. Kumar, R. Rani, Ecotoxicol. Environ. Safety, 147, 1035 (2018)

3. M.L. Sanchez, Causes and Effects of Heavy Metal Pollution (Newyark: Nova Science Publishers, Inc., 2009)

4. X. Lu, X. Xu, Y. Zhang, Y. Zhang, C. Wang, X. Huo, Environ. Poll. 234, 601 (2018)

5. G. Bertin, D. Averbeck, Biochim. 88, 1549 (2006)

6. K. Rehman, F. Fatima, I. Waheed, M.S.H. Akash, J. Cell Biochem. 119, 157 (2018)

7. https://www.epa.gov/ground-water-and-drinkingwater/national-primary-drinking-water-regulations (Accessed 1 July 2018)

8. P.T. Anastas, M.M. Kirchhoff, Acc. Chem. Res. 35, 686 (2002)

9. P.T. Anastas, J.C. Warner, Green Chemistry: Theory and Practice (Oxford University Press, New York, 1998)

10. M. Sophocleous, J.K. Atkinson, Sens. Act. A: Phys. 267, 106 (2017)

11. P. Bollella, G. Fusco, D. Stevar, L. Gorton, R. Ludwig, S. Ma, H. Boer, A. Koivula, C. Tortolini, G. Favero, R. Antiochia, F. Mazzei, Sens. Act. B: Chem. 256, 921 (2018)

12. P. Nicholas, R. Pittson, J.P. Hart, Food Chem. 241, 122 (2018)

13. C. Pérez-Ràfols, P. Trechera, N. Serrano, J.M. DíazCruz, C. Ariño, M. Esteban, Talanta, 167, 1 (2017)

14. H. Jo, J. Her, H. Lee, Y. Shim, C. Ban, Talanta, 165, 442 (2017)

15. I. Shitanda, T. Irisako, M. Itagaki, Sens. Act. B: Chem. 160, 1606 (2011)

16. A. Mandil, L. Idrissi, A. Amine, Microchim. Act. 170, 299 (2010)

17. S. Rana, S.K. Mittal, N. Kaur, C.E. Banks, Sens. Act. B: Chem. 249, 467 (2017)

18. D. Chen, Z. Liu, J. Fu, Y. Guo, X. Sun, Q. Yang, X. Wang, J. Electroanalyt. Chem. 801, 185 (2017)

19. J. Wang, Electroanal. 17, 1341 (2005)

20. A. Economou, Trends Anal. Chem. 24, 334 (2005)

21. Z.Q. Wang, G. Liu, L.N. Zhang, H. Wang, Int. J. Electrochem. Sci. 7, 12326 (2012)

22. R. Pauliukaite, S.B. Hocevar, B. Ogorevc, J. Wang, Electroanal. 16, 719 (2004)

23. L. Baldrianova, I. Svancara, A. Economou, S. Sotiropoulos, Anal. Chim. Acta 580, 24 (2006)

24. C. Kokkinos, A. Economou, I. Raptis, T. Speliotis, Electrochem. Commun. 13, 391 (2011)
25. G.J. Lee, H.M. Lee, C.K. Rhee, Electrochem. Commun. 9, 2514 (2007)

26. S. Lee, S. Park, E. Choi, Y. Piao, J. Electroanalyt. Chem. 766, 120 (2016)

27. Z. Wang, H. Wang, Z. Zhang, G. Liu, Sens. Act. B: Chem. 199, 7 (2014)

28. K. Keawkim, S. Chuanuwatanakul, O. Chailapakul, S. Motomizu, Food Contr. 31, 14 (2013)

29. A. Królicka, A. Bobrowski, Electrochim. Acta, 187, 224 (2016)

30. X. Xuan, J.Y. Park, Sens. Act. B: Chem. 255, 1220 (2018)

31. M.A.G. Rico, M. Olivares-Marín, E.P. Gil, Talanta, 80, 631 (2009)

32. M.A.E. Mhammedi, M. Bakasse, A. Chtaini, J. Hazard. Mater. 145, 1 (2007)

33. A.A.A. Khan, M.A. Abdullah, Int. J. Electrochem. Sci. 8, 195 (2013)

34. H. Ajab, J.O. Dennis, M.A. Abdullah, Int. J. Biol. Macromol. 113, 376 (2018)

35. DropSens, Screen printed electrode (2012)

36. ICH, International Conference on Harmonization of Technical Requirements for the Registration of Pharmaceuticals for Human Use (Geneva, 1996)

37. A.F. Al-Ghamdi, M.M. Hefnawy, A.A Al-Majed, F.F. Belal, Chem. Centr. J. 6, 15 (2012)

38. M. Vila, S. Sánchez-Salcedo, M. Vallet-Regí, Inorganic Chim. Acta, 393, 24 (2012)

39. G. Milazzo, S. Caroli, R.D. Braun, J. Electrochem. Soc. 125, 261C (1978)

40. F. Scholz, AM Bond, Electroanalytical methods: guide to experiments and applications (Springer Verlag, 2010)

41. D.A. Skoog, D.M. West, F.J. Holler, S. Crouch, Fundamentals of analytical chemistry (Nelson Education, 2013)

42. M.A. El Mhammedi, M. Achak, A. Chtaini, J. Hazard. Mater. 161, 55 (2009)

43. S. Chuanuwatanakul, W. Dungchai, O. Chailapakul, S. Motomizu, Analyt. Sci. 24, 589 (2008)

44. R.O. Kadara, I.E. Tothill, Analyt. Chim. Acta, 623, $76(2008)$ 